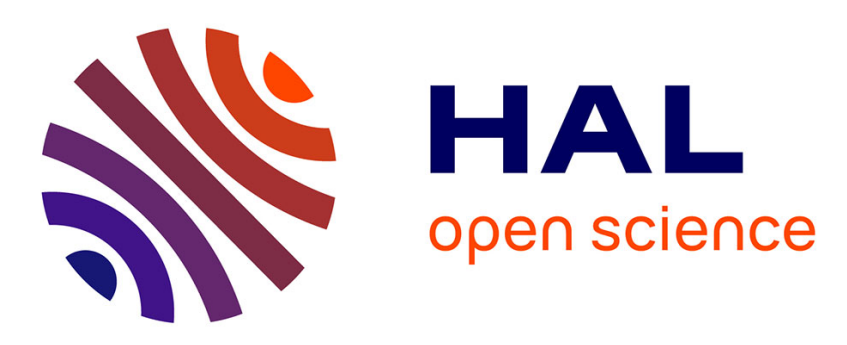

\title{
Allyloxy ketones as efficient photoinitiators with high migration stability in free radical polymerization and $3 \mathrm{D}$ printing
}

Yangyang Xu, Guillaume Noirbent, Damien Brunel, Zhaofu Ding, Didier Gigmes, Bernadette Graff, Pu Xiao, Frédéric Dumur, Jacques Lalevée

\section{To cite this version:}

Yangyang Xu, Guillaume Noirbent, Damien Brunel, Zhaofu Ding, Didier Gigmes, et al.. Allyloxy ketones as efficient photoinitiators with high migration stability in free radical polymerization and 3D printing. Dyes and Pigments, 2021, 185, pp.108900. 10.1016/j.dyepig.2020.108900 . hal-02958467

\section{HAL Id: hal-02958467 https://hal.science/hal-02958467}

Submitted on 5 Oct 2020

HAL is a multi-disciplinary open access archive for the deposit and dissemination of scientific research documents, whether they are published or not. The documents may come from teaching and research institutions in France or abroad, or from public or private research centers.
L'archive ouverte pluridisciplinaire $\mathbf{H A L}$, est destinée au dépôt et à la diffusion de documents scientifiques de niveau recherche, publiés ou non, émanant des établissements d'enseignement et de recherche français ou étrangers, des laboratoires publics ou privés. 


\title{
Allyloxy ketones as efficient photoinitiators with high migration
}

\section{stability in free radical polymerization and 3D printing}

Yangyang Xu, ${ }^{\mathrm{a}, \mathrm{b}, \mathrm{c}^{*}}$ Guillaume Noirbent, ${ }^{\mathrm{d}}$ Damien Brunel, ${ }^{\mathrm{d}}$ Zhaofu Ding, ${ }^{\mathrm{a}}$ Didier Gigmes, ${ }^{\mathrm{d}}$ Bernadette Graff, ${ }^{\mathrm{b}, \mathrm{c}} \mathrm{Pu}$ Xiao, ${ }^{\text {e* }}$ Frédéric Dumur ${ }^{\mathrm{d}^{*}}$ and Jacques Lalevée ${ }^{\mathrm{b}, \mathrm{c}^{*}}$

${ }^{a}$ College of Chemistry and Materials Science, Anhui Normal University, South Jiuhua Road 189, Wuhu 241002, China. E-mail: ahnuxyy@ahnu.edu.cn

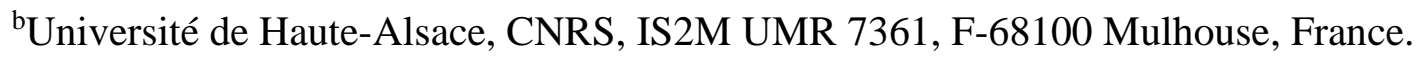

E-mail: jacques.lalevee@uha.fr

'Université de Strasbourg, France.

${ }^{\mathrm{d} A i x}$ Marseille Univ, CNRS, ICR UMR 7273, F-13397 Marseille, France. E-mail: Frederic.dumur@univ-amu.fr

${ }^{\mathrm{e}}$ Research School of Chemistry, Australian National University, Canberra, ACT 2601, Australia. E-mail: pu.xiao@anu.edu.au

\begin{abstract}
Five ketone derivatives (ketone-1 ketone-5) never synthesized in the literature and containing the same peripheral 1,3-bis(allyloxy)benzene substituting group but different central cyclohexanone cores were designed and proposed as highperformance photoinitiators for the free radical polymerization of acrylates under mild conditions. In combination with an amine and an iodonium salt (Iod), these ketones could initiate the photopolymerization of di(trimethylolpropane) tetraacrylate (TA), a tetrafunctional acrylates monomer, upon visible LED irradiation at room temperature in both thick films $(1.4 \mathrm{~mm})$ and thin films $(25 \mu \mathrm{m})$ conditions. The distinct photopolymerization profiles of acrylates were studied by real time Fourier transform infrared spectroscopy, which indicated that the ketone-2/amine/Iod system could induce the highest final conversion of acrylates in thick films condition, while ketone5/amine/Iod system could induce the highest final conversion of acrylates in thin films condition. Photoreactivity of ketone- 2 and ketone- 5 was systematically investigated by steady state photolysis and fluorescence quenching experiments in the presence of an amine and an iodonium salt, respectively. Moreover, eminent migration stability of ketones in photocured TA was observed. Finally, the ketone- 2 and ketone-5-based three-component photoinitiating systems were applied for the laser writing experiments of TA, and macroscopically tridimensional patterns were fabricated with an excellent spatial resolution.
\end{abstract}




\section{Introduction}

The polymerization process triggered by light, i.e. photopolymerization reaction, has appealed tremendous research interest and achieved great development in the last decades. Compared with the traditional thermal activation, photopolymerization is characterized with apparent superiorities, including fast reaction rates, mild conditions (e.g., room temperature) with less energy consumption, green technology without volatile organic compounds release, as well as outstanding temporal and spatial controllability. ${ }^{1-5}$ Therefore, the photopolymerization strategy has been obtaining a wide attention in not only scientific research area, but also in the manufacturing field. Especially, the photocuring 3D printing is a good example for the application of efficient photopolymerization under mild conditions: light-emitting diode (LED) projector irradiation at room temperature under air. Meanwhile, this 3D printing technology requires highly active photoinitiating systems developed to give access to thick or filled samples upon visible LED irradiation. ${ }^{6-10}$

However, until now, many photopolymerization reactions are still limited to UV irradiation, although the UV light with high intensity is usually harmful and dangerous. ${ }^{11,12}$ Therefore, the exploration for photopolymerization sensitive to visible light with low ecological impact is becoming the research subject of huge interest. ${ }^{13,14}$ In this direction, compared with UV-induced polymerization, the usage of photopolymerizable matrices adapted to visible LED irradiation demonstrates many advantages, such as eco-friendliness without use of harmful UV rays and ozone release, higher operating efficiency with low heat generation, lower operating costs with cheap sources, long lifetimes with low maintenance costs and so on. ${ }^{15-17}$ The key point towards the visible LED induced photopolymerization is the exploitation of effective photoinitiating systems that would generate radicals or ions to initiate the polymerization reaction of monomers upon LED activation. The efficiency of photoinitiators is strongly govern by the choice of the excitation wavelength.

Despite the promising prospect of high photoinitiation efficiency, the extractability of small molecule-based initiators remains a key issue, since the migration of unreacted species to the surface of photocured polymers can cause potential impediment for the future application of resulting polymer materials. ${ }^{18,19}$ The ketone moiety is well-known for its absorption in the visible/near UV region. Previously, we have developed several series of ketones derivatives as photoinitiators for the photopolymerization upon visible LED irradiation. ${ }^{20-22}$ However, the reported ketone-based photoinitiators may suffer from the poor migration stability as classical commercial photoinitiators. Therefore, it would be very interesting if the ketones can act not only as photoinitiators, but also as monomers participating in the photopolymerization through a co-polymerizable moiety, which can address the migration issue. To achieve this goal, polymerizable groups such as styrenes, acrylates, methacrylates or allyl groups can be introduced as peripheral groups of photoinitiators and several examples of crosslinkable photoinitiators have been reported with 
naphthalimides. ${ }^{23-26}$ Considering the strategy used to synthesize the different ketones (i.e. the Claisen-Schmidt condensation in basic conditions), the allyl group was selected as the appropriate polymerizable group due to its remarkable stability in strongly basic conditions, but also due to its facile introduction on the ketone backbone.

Herein, five ketone derivatives substituted by the same peripheral 1,3bis(allyloxy)benzene group are elaborately designed and synthesized for the first time. In combination with an amine and an iodonium salt, these ketones can form threecomponent photoinitiating systems for the free radical polymerization of acrylates. The different central cyclohexanone structures would lead to distinct photoinitiation abilities, which are studied by real-time Fourier transform infrared spectroscopy. Besides, the ketone/Iod two-component system was also investigated for the cationic polymerization of epoxides. Photoreactivity of representative ketones in the presence of an amine and an iodonium salt, respectively, was systematically investigated with steady state photolysis and fluorescence characterizations. In addition, the migration of ketones from the synthesized photopolymer was investigated. Finally, the application of these ketones-based three-component photoinitiating systems for the LED projector photocuring 3D printing on acrylates is also studied.

\section{Experimental section}

\subsection{Materials}

Five ketone derivatives substituted with 1,3-bis(allyloxy)benzene groups were synthesized according to the procedures depicted in detail in the ESI (Scheme S1) and their corresponding chemical structures were presented in Scheme 1. A reference compound (noted ketone-ref) substituted with aliphatic chains was also synthesized for comparison. The amine, ethyl 4-(dimethylamino)benzoate (EDB), and the iodonium salt, di-tert-butyl-diphenyliodonium hexafluorophosphate (Iod, commercial name: Speedcure 938) were obtained from Lambson Ltd. Di(trimethylolpropane) tetraacrylate (TA, commercial name: Ebecryl 40) and (3,4-epoxycyclohexane)methyl 3,4epoxycyclohexylcarboxylate (EPOX, commercial name: Uvacure 1500) were purchased from Allnex and used as the benchmark monomers for the free radical photopolymerization and cationic polymerization, respectively. Noticeably, TA contained 1000 ppm monomethyl ether hydroquinone as storage inhibitor, which wasn't removed before photopolymerization reaction. All these commercially available chemical compounds were selected with the highest purity and used as received, and their chemical structures are shown in Scheme 2. 
<smiles>C=CCOc1ccc(/C=C2\CCC/C(=C\c3ccc(OCC=C)cc3OCC=C)C2=O)c(OCC=C)c1</smiles>

Ketone-1<smiles>C=CCOc1ccc(/C=C2\CC(C(C)(C)C)C/C(=C\c3ccc(OCC=C)cc3OCC=C)C2=O)c(OCC=C)c1</smiles>

Ketone-3<smiles>C=CCOc1ccc(/C=C2\CN(CC)C/C(=C\c3ccc(OCC=C)cc3OCC=C)C2=O)c(OCC=C)c1</smiles>

Ketone-5<smiles>C=CCOc1ccc(/C=C2\CC(C)C/C(=C\c3ccc(OCC=C)cc3OCC=C)C2=O)c(OCC=C)c1</smiles>

Ketone-2<smiles>C=CCOc1ccc(/C=C2\CSC/C(=C\c3ccc(OCC=C)cc3OCC=C)C2=O)c(OCC=C)c1</smiles>

Ketone-4<smiles>CCCCOc1ccc(/C=C2\CN(CC)C/C(=C\c3ccc(OCCC)cc3OCCC)C2=O)c(OCCCC)c1</smiles>

Ketone-Ref

Scheme 1. Chemical structures of the investigated ketone derivatives.<smiles>CCOC(=O)c1ccc(N(C)C)cc1</smiles>

EDB<smiles>C=CC(=O)OCC(CC)(COCC(CC)(COC(=O)C=C)COC(=O)C=C)COC(=O)C=C</smiles>

TA<smiles>CC(C)Cc1ccc([Al](c2ccc(CC(C)C)cc2)c2ccc(C(C)C)cc2)cc1</smiles>

Iod<smiles>O=C(OCC1CCC2OC2C1)C1CCC2OC2C1</smiles>

EPOX

Scheme 2. Chemical structures of the photo-additives (EDB and iodonium salt (Iod)) and the benchmark monomers (TA and EPOX).

\subsection{Formulation preparation}

The weight percent of the ketones-based photoinitiating systems was calculated from the monomer content (Table S1). In terms of the free radical polymerization, different kinds of ketones, amine and iodonium salt, forming three-component photoinitiating systems $(0.1 \% / 2 \% / 2 \%$, w/w/w), were successively added into colorless TA resin. Then, upon the strong mechanical mixing by a SpeedMixer (DAC 150.1 FVZ-K) with rotation speed at $2000 \mathrm{rpm}$ for several minutes, a homogeneous resin 
could be produced with yellow color (Figure S1). In terms of the cationic polymerization, ketones and iodonium salt, forming two-component photoinitiating systems $(0.1 \% / 2 \%, \mathrm{w} / \mathrm{w})$, were added into colorless EPOX. Also, similar mixing process was conducted with the same SpeedMixer to produce a yellow resin. In order to avoid pre-polymerization, all of the prepared formulations were stored in a dark environment at room temperature before LED irradiation.

\subsection{Irradiation source}

A visible LED with the maximum emission wavelength at $405 \mathrm{~nm}\left(\lambda_{\text {emi }}=405 \mathrm{~nm}\right)$ was utilized as the irradiation source for both the free radical and cationic polymerizations. The incident light intensity at the sample surface was set about 110 $\mathrm{mW} / \mathrm{cm}^{2}$ and the light spot was about $3 \mathrm{~cm}$ in diameter. Another LED with the maximum emission wavelength at $375 \mathrm{~nm}\left(\lambda_{e m i}=375 \mathrm{~nm}\right)$ was used as the irradiation source for the photolysis experiments, and the intensity of this light source was about $40 \mathrm{~mW} / \mathrm{cm}^{2}$.

\subsection{Real-time Fourier transform infrared spectroscopy}

The free radical polymerization of acrylates was performed in both thick films $(1.4 \mathrm{~mm})$ and thin films $(25 \mu \mathrm{m})$ conditions. Meanwhile, the cationic polymerization of epoxides was only successfully performed in thin films $(25 \mu \mathrm{m})$ conditions. For the free radical photopolymerization carried out in thick films condition, the prepared photosensitive formulations were deposited into a mold with $1.4 \mathrm{~mm}$ thickness. For the photopolymerization in thin films condition, one drop formulation was deposited between two polypropylene films with about $25 \mu \mathrm{m}$ in thickness. All the photopolymerization experiments were carried out in laminate (the formulation is sandwiched between two polypropylene films to reduce the oxygen inhibition) under mild conditions: upon the irradiation of visible LED@ $405 \mathrm{~nm}$ at room temperature. The real time Fourier transform infrared spectroscopy (RT-FTIR, JASCO FTIR 4100) method was used to quantitatively characterize the photopolymerizations by continuously following the evolution of the double bond content of TA $(\mathrm{C}=\mathrm{C}$ at 4740 $\mathrm{cm}^{-1}$ for thick films or at $1630 \mathrm{~cm}^{-1}$ for thin films) and the epoxide group content of EPOX (monitored at $\sim 800 \mathrm{~cm}^{-1}$ for thin films), respectively. The final conversion (FC) of the reactive groups was determined by measuring the peak area of the relevant characteristic peaks at certain irradiation time:

$$
\mathrm{FC}(\%)=\left[1-\mathrm{A}_{t} / \mathrm{A}_{0}\right] \times 100
$$

where $A_{0}$ is the initial peak area of reactive groups before LED irradiation and $A_{t}$ is the corresponding peak area after the LED irradiation for a certain time $t$.

\subsection{UV-visible absorption spectroscopy and steady state photolysis experiments}

The UV-visible absorption properties of the five designed ketones in acetonitrile as well as the steady state photolysis experiments were studied by JASCO V730 UVvisible spectrometer.

\subsection{Fluorescence quenching experiments}


A JASCO FP-6200 spectrofluorimeter was used to study the fluorescence properties of the ketone derivatives dissolved in acetonitrile with an excitation wavelength at $320 \mathrm{~nm}$, and the specific experimental conditions are presented in the corresponding figures.

\subsection{Computational procedure}

Geometry optimizations were carried out with the Gaussian 03 suite of programs at $\mathrm{uB} 3 \mathrm{LYP} / 6-31 \mathrm{G}^{*}$ level. ${ }^{27}$ Geometries were frequency checked. The electronic absorption spectra were calculated from the time-dependent density functional theory (TD-DFT) at MPW1PW91/6-31G* level of theory on the relaxed geometries calculated at the $\mathrm{uB} 3 \mathrm{LYP} / 6-31 \mathrm{G}^{*}$ level of theory.

\subsection{Photoinitiator migration study}

Migration tests of the ketone-based photoinitiators from the finally synthesized polymers were carried out in acetonitrile. About $0.2 \mathrm{~g}$ TA was polymerized in the presence of ketone/amine/Iod $(0.1 \% / 2 \% / 2 \%$, w/w/w) systems. The polymerized pellet was cut into small pieces and immersed in $5 \mathrm{~mL}$ of acetonitrile overnight. The amount of extracted photoinitiator was determined by UV-visible absorption spectroscopy. The percentage of ketone migration was calculated as:

$$
\text { extracted }(\%)=\left[\mathrm{m}_{\text {extracted }} / \mathrm{m}_{\text {initial }}\right] \times 100
$$

where $m_{\text {extracted }}$ and $m_{\text {initial }}$ are the weight of ketones extracted from the polymer and the weight of ketones present initially in the polymer pellet, respectively. ${ }^{28}$

\subsection{Laser writing experiments}

For the laser write experiments to produce macroscopic 3D patterns, a computer programmed laser diode (Thorlabs) was used for the spatially controlled irradiation with an emission wavelength at $405 \mathrm{~nm}$. The spot size of the laser was about $50 \mu \mathrm{m}$ and the intensity of the laser at sample's surface was about $110 \mathrm{~mW} / \mathrm{cm}^{2}$ to keep in line with the RT-FTIR kinetics experiments. The TA resin containing ketones-based photoinitiating systems was deposited into a homemade tank. The laser write experiments of the resin were conducted under air at room temperature. And the generated 3D patterns were observed and analyzed through a numerical optical microscope (DSX-HRSU, OLYMPUS corporation).

\section{Results and discussion}

\subsection{Synthesis of the five ketone derivatives}

The five ketones, denoted as ketone-1 ketone-5, share the same peripheral substituting group (allyloxy group) but different central cyclohexanones. The general synthetic routes to these ketones are illustrated in Scheme 3, while the detailed synthetic methods and structural analysis of the targeted ketones are described in the ESI. Briefly, ketones-1 5 were prepared by a Claisen-Schmidt condensation in basic conditions, enabling to synthesize the five ketones with reaction yields ranging from $82 \%$ (for ketone-3) to $93 \%$ (for ketone 2). It has to be noticed that none of the ketones examined in this work have been previously reported in the literature. To evidence the benefits of 
the polymerizable groups on the extractability issue, an analogue of ketone-5 was also synthesized, possessing butoxy groups (noted ketone-ref) instead of allyloxy groups. This molecule could be prepared in $85 \%$ yield, close to that obtained for its parent ketone-5 (89\% yield).<smiles>[R]C1CCC(=O)CC1</smiles><smiles>C=CCOc1ccc(C=O)c(OCC=C)c1</smiles><smiles>C=CCOc1ccc(C=O)c(OCC=C)c1</smiles><smiles>CCN1CCC(=O)CC1</smiles><smiles>CC(C)OC(=O)O</smiles><smiles>CCN1CCC(=O)CC1</smiles><smiles>[R]C1CC(=Cc2ccc(OCC=C)cc2OCC=C)C(=O)C(=Cc2ccc(OCC=C)cc2OCC=C)C1</smiles>

Ketone- $1: \mathrm{R}=\mathrm{H}, 85 \%$ yield Ketone-2: $\mathrm{R}=\mathrm{CH}_{3}, 93 \%$ yield Ketone- $3: \mathrm{R}=$ tert $-\mathrm{Bu}, 82 \%$ yield<smiles>C=CCOc1ccc(/C=C2\CSC/C(=C\c3ccc(OCC=C)cc3OCC=C)C2=O)c(OCC=C)c1</smiles>

Ketone-4<smiles>C=CCOc1ccc(/C=C2\CN(CC)C/C(=C\c3ccc(OCC=C)cc3OCC=C)C2=O)c(OCC=C)c1</smiles>

Ketone-5<smiles>CCCCCOc1cc(OCCCC)ccc1/C=C1\CN(CC)C/C(=C\c2ccc(OCCC)cc2OCC)C1=O</smiles>

Ketone-ref

Scheme 3. General synthetic routes to the five ketone derivatives and the reference ketone (noted ketone-ref).

\subsection{UV-visible absorption property of ketones}

Light absorption properties of these five ketone derivatives were studied in acetonitrile, and their UV-visible absorption spectra are shown in Figure 1 and Figure S2. For clarity, absorption spectrum of ketone-ref is not presented as the replacement of allyloxy groups in ketone- 5 by butoxy groups in ketone-ref is without influence on the positions of the absorption bands. In addition, the theoretical absorption property of the different ketones determined by TD-DFT calculation proved to be in good agreement with the experimental results (Figure S3). Besides, the maximum absorption $\left(\lambda_{\max }\right)$ as well as the molar extinction coefficients at $\lambda_{\max }$ (i.e. $\left.\varepsilon_{\max }\right)$ and $405 \mathrm{~nm}$ (i.e. $\varepsilon_{405}$ $\left.{ }_{\mathrm{nm}}\right)$ are summarized in Table 1. $\lambda_{\max }$ of all these five ketones were between $355 \mathrm{~nm}$ and 
$370 \mathrm{~nm}$, while their corresponding molar extinction coefficients $\left(\varepsilon_{\max }\right)$ varied from $19000 \mathrm{M}^{-1} \mathrm{~cm}^{-1}$ to $26000 \mathrm{M}^{-1} \mathrm{~cm}^{-1}$. The differences in the light absorption properties of these ketones would probably be ascribed to their various central cyclohexanone structures, since they all shared the same peripheral substituting group. Interestingly, all ketones also exhibited an obvious absorption at $405 \mathrm{~nm}$ with the relevant molar extinction coefficients $\left(\varepsilon_{405} \mathrm{~nm}\right)$ in the range of $7000-14000 \mathrm{M}^{-1} \mathrm{~cm}^{-1}$, among which ketone-5 showed the highest $\varepsilon_{405 \mathrm{~nm}}$ value $\left(13800 \mathrm{M}^{-1} \mathrm{~cm}^{-1}\right)$ while ketone- 4 showed the lowest $\varepsilon_{405 \mathrm{~nm}}$ value $\left(7600 \mathrm{M}^{-1} \mathrm{~cm}^{-1}\right)$. The intensive absorption of the introduced ketones at $405 \mathrm{~nm}$ promised a good overlap with the emission spectra of the violet LED@ 405 $\mathrm{nm}$ used in this work as the irradiation source for the photopolymerizations.

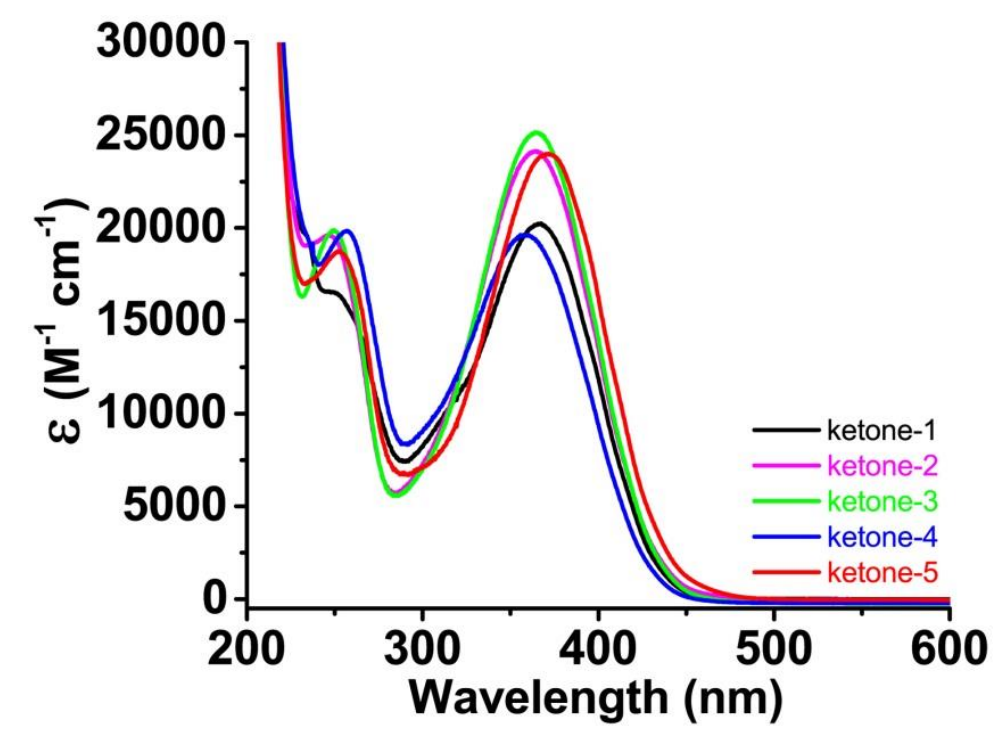

Figure 1. UV-visible absorption spectra of the five ketones dissolved in acetonitrile.

Table 1. Summary of light absorption properties of the five ketones: absorption maxima wavelengths $\left(\lambda_{\max }\right)$, molar extinction coefficients at $\lambda_{\max }\left(\varepsilon_{\max }\right)$ and at 405 $\mathrm{nm}\left(\varepsilon_{405} \mathrm{~nm}\right)$, respectively.

\begin{tabular}{|c|c|c|c|c|}
\hline & $\begin{array}{c}\text { calculated } \\
\lambda_{\max }(\mathrm{nm})\end{array}$ & $\lambda_{\max }(\mathrm{nm})$ & $\varepsilon_{\max }\left(\mathrm{M}^{-1} \mathrm{~cm}^{-1}\right)$ & $\varepsilon 405 \mathrm{~nm}\left(\mathrm{M}^{-1} \mathrm{~cm}^{-1}\right)$ \\
\hline ketone-1 & 365 & 366 & 20200 & 9800 \\
\hline ketone-2 & 365 & 364 & 24200 & 11100 \\
\hline ketone-3 & 367 & 364 & 25200 & 11500 \\
\hline ketone-4 & 356 & 357 & 19700 & 7600 \\
\hline ketone-5 & 361 & 370 & 24000 & 13800 \\
\hline
\end{tabular}

Optimized geometries of the different ketones as well as their frontier orbitals (lowest unoccupied molecular orbital, i.e. LUMO, and highest occupied molecular orbital, i.e. HOMO) were predicted by the TD-DFT theoretical calculations and the contour plots are depicted in Figure 2. As shown in the Figure 2, both the LUMO and HOMO are delocalized over the whole $\pi$-conjugated system. Due to the weak electrondonating ability of the peripheral groups and the poor electron-accepting ability of the 
central ketone group, the maximum absorption for all dyes was observed at rather high energy (e.g. in the $350-370 \mathrm{~nm}$ range).

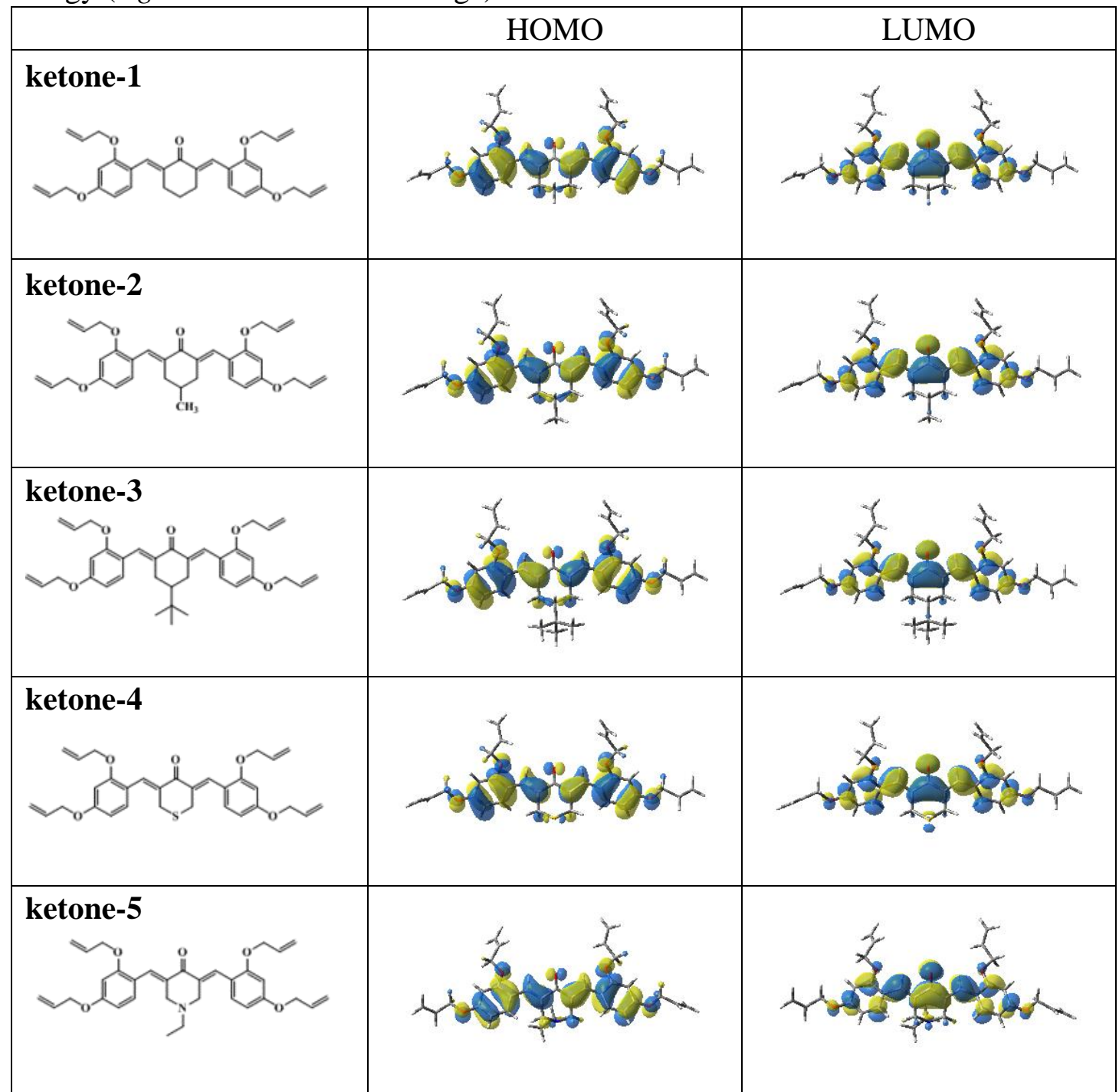

Figure 2. Contour plots of the highest occupied molecular orbitals (HOMOs) and lowest unoccupied molecular orbitals (LUMOs) for the five investigated ketone derivatives: structures optimized at uB3LYP/6-31G* Level.

\subsection{Free radical photopolymerization of TA}

The free radical polymerization of TA, a tetrafunctional acrylates monomer, was initiated by different ketone/amine/Iod three-component photoinitiating systems in both thick films $(1.4 \mathrm{~mm})$ and thin films $(25 \mu \mathrm{m})$ conditions upon irradiation of LED@ 405 $\mathrm{nm}$. Photoinitiation abilities of the five ketone derivatives were compared and studied in detail. Typical acrylate function conversion profiles against the violet LED irradiation time are illustrated in Figure 3 through the RT-FTIR method, meanwhile the final conversions (FCs) of reactive acrylate groups are summarized in Table 2. Although the UV-visible absorption spectra demonstrated that the five ketones showed a relatively strong absorption at $405 \mathrm{~nm}$ (i.e. the maximum emission wavelength of the violet LED), the photoinitiation abilities of the different ketones, in combination with 
the amine and the iodonium salt, differed dramatically. On the one hand, for the free radical polymerization of acrylates in thick films condition shown in Figure 3a, the five photopolymerization profiles exhibited a long induction time (i.e. a period of oxygen inhibition), and the photopolymerization started only $100 \mathrm{~s}$ after the LED irradiation was switched on. Among the different ketones-based three-component photoinitiating systems, ketone- 2 could induce the highest FC of acrylates (about $82 \%$ ), while ketone1 could induce the lowest one (about 57\%). Photoinitiation abilities of the five ketone derivatives, in combination with amine and iodonium salt, followed the order: ketone$2>$ ketone-4>ketone-5>ketone-3>ketone-1. An inner filter effect can be suspected in thick films due to the high extinction coefficient of the ketone (absorbance@405nm > 2 for a thickness of $1.4 \mathrm{~mm}$ ). On the other hand, as shown in Figure $3 \mathrm{~b}$ for the free radical polymerization of acrylates in thin films condition, photopolymerization of acrylates took place immediately without delay i.e. this inner filter effect does not occur. Among all the ketones/amine/Iod three-component photoinitiating systems, ketone-5 could induce the highest FC of acrylates (about 73\%), while ketone-2 led to the lowest one (about 52\%). And the photoinitiation abilities of the five ketone derivatives, in combination with the amine and the iodonium salt, were in the sequence as: ketone$5>$ ketone-3>ketone-4>ketone-1>ketone-2. This trend is not only related to their light absorption properties as ketone 4 is more reactive than ketone 2 despite a lower extinction coefficient. The different trends of acrylates conversions induced by ketonesbased photoinitiating systems in thick and thin films were possibly caused by the inner filter effect, since light penetration decreases for thick samples. ${ }^{29}$ This suggests that the electron and hydrogen transfer reactions from their excited states play a significant role on their initiating ability.

Besides, the slopes of the kinetics profiles (i.e. polymerization rate), obtained right after the beginning of polymerization, also indicated that the ketones illustrated better photoinitiation performance in thin films condition than that in thick films condition.
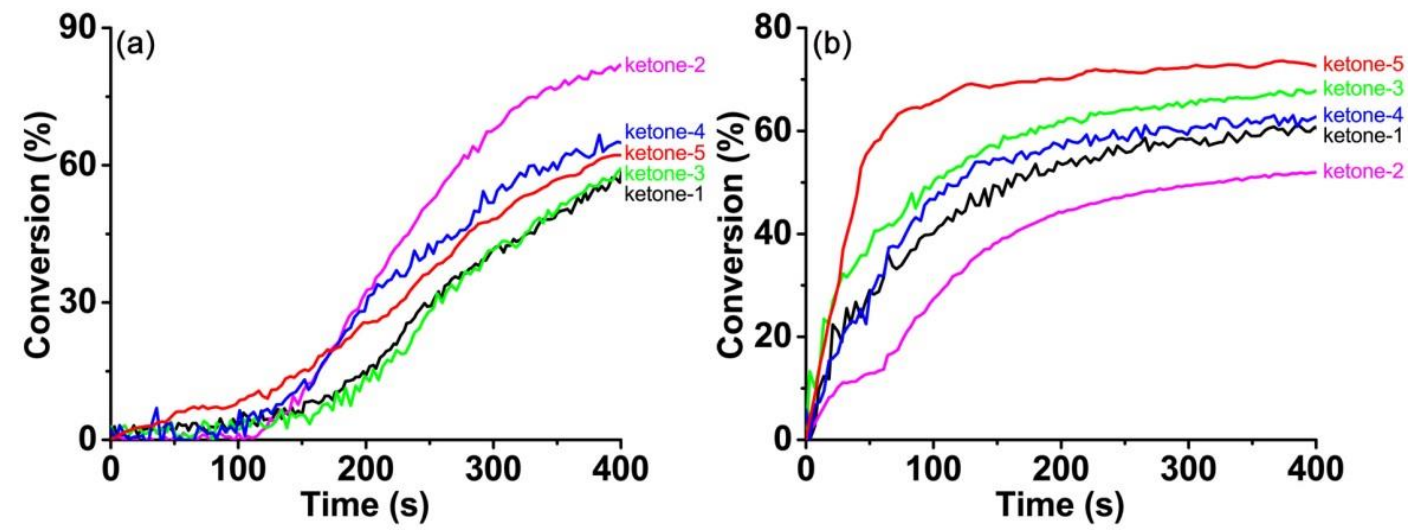

Figure 3. Free radical photopolymerization profiles of $\mathrm{TA}$ (conversion of $\mathrm{C}=\mathrm{C}$ bonds versus irradiation time) initiated by the ketone/amine/Iod $(0.1 \% / 2 \% / 2 \%, \mathrm{w} / \mathrm{w} / \mathrm{w})$ three- 
component systems upon violet LED@405 nm irradiation at room temperature: (a) in thick films condition $(1.4 \mathrm{~mm})$ and $(\mathrm{b})$ in thin films condition $(25 \mu \mathrm{m})$, respectively.

Table 2. Final conversions (FCs) for reactive acrylate functions of TA upon exposure to LED@ $405 \mathrm{~nm}$ for $400 \mathrm{~s}$ in the presence of ketone/amine/Iod $(0.1 \% / 2 \% / 2 \%$, w/w/w) three-component photoinitiating systems in thick and thin films conditions, respectively.

\begin{tabular}{|c|c|c|c|c|c|}
\hline \multirow{2}{*}{$\begin{array}{c}\text { FCs } \\
\text { (in thick) }\end{array}$} & ketone-1 & ketone-2 & ketone-3 & ketone-4 & ketone-5 \\
\cline { 2 - 6 } & $57 \%$ & $82 \%$ & $59 \%$ & $65 \%$ & $62 \%$ \\
\hline \multirow{2}{*}{$\begin{array}{c}\text { FCs } \\
\text { (in thin) }\end{array}$} & ketone-1 & ketone-2 & ketone-3 & ketone-4 & ketone-5 \\
\cline { 2 - 6 } & $60 \%$ & $52 \%$ & $68 \%$ & $63 \%$ & $73 \%$ \\
\hline
\end{tabular}

Since ketone- 2 and ketone-5 based three-component systems showed the highest photoinitiation efficiencies for the free radical polymerization in thick films and thin films conditions, respectively, the IR spectra of acrylates before and after LED@405 $\mathrm{nm}$ irradiation were further compared and investigated (Figure 4). As shown in Figure $4 \mathrm{a}$, for the free radical polymerization initiated by ketone-2/amine/Iod in thick films condition, a vigorous intensity decrement was observed for the acrylate peak at about $4740 \mathrm{~cm}^{-1}$ (for thick samples, NIR was used to monitor the polymerization process). ${ }^{10,30}$ While for the free radical polymerization initiated by ketone-5/amine/Iod in thin films condition, also a significant intensity decrement could be observed for the acrylates stretching band at about $1630 \mathrm{~cm}^{-1}$ (Figure $4 \mathrm{~b}$ ). ${ }^{31,32}$ Previous research has revealed that neither iodonium salt (Speedcure 938) nor amine (EDB) alone could induce the free radical polymerization of acrylates in the same conditions. ${ }^{33,34}$ Although the charge transfer complex, formed by EDB/Iod two components, can be used to initiate the free radical polymerization effectively in thick films condition, its initiation ability was quite poor in thin films condition, as shown in Figure S4. ${ }^{35}$ And in this work, with the formation of ketone/amine/Iod three-component systems, the free radical polymerization efficiency in thin films condition could be significantly improved. All the photopolymerization kinetics experiments demonstrated that the ketones introduced in this work, in combination with amine and iodonium salt, can be excellent candidates as high performance photoinitiators for the free radical polymerization under mild conditions. 

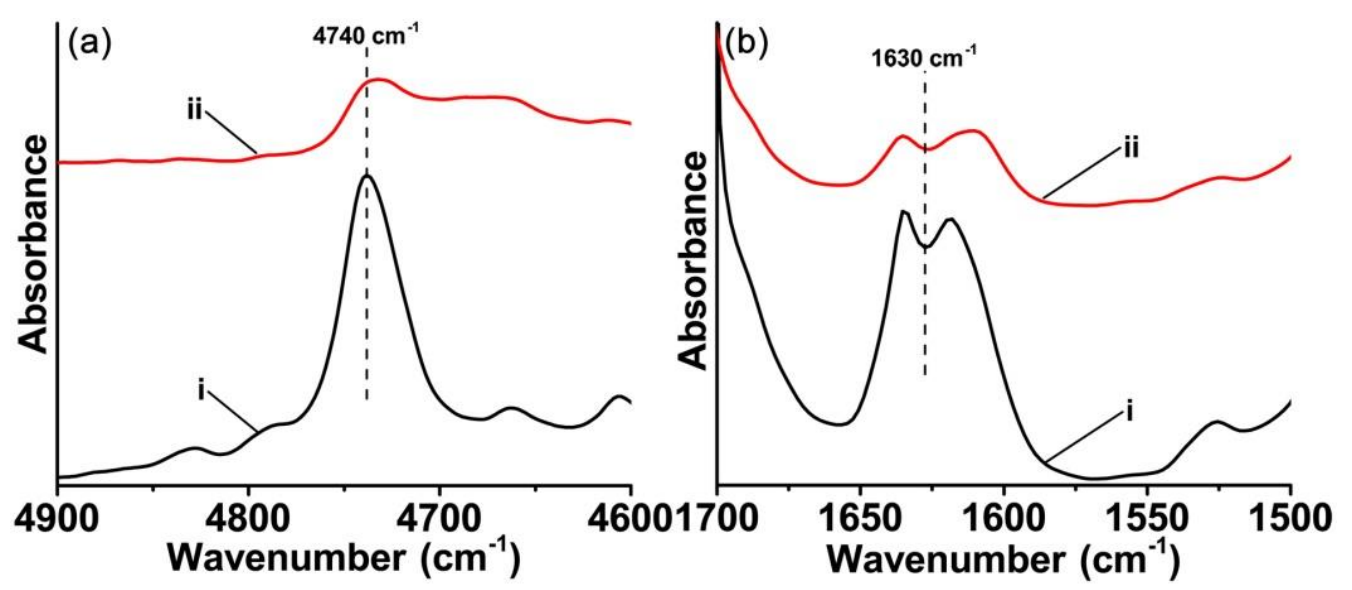

Figure 4. In-situ IR spectra recorded for TA (i) before and (ii) after the irradiation of LED@405 nm for $400 \mathrm{~s}$ in the presence of (a) ketone-2/amine/Iod in thick films condition and (b) ketone-5/amine/Iod in thin films condition, respectively.

\subsection{Cationic photopolymerization of EPOX}

The high photoinitiation abilities of ketones for the free radical polymerization of acrylates inspired us to explore their ability for the cationic polymerization of epoxides. Our previous research has revealed that the photopolymerization of epoxides could not happen in the presence of the iodonium salt alone in the investigated conditions. ${ }^{36,37}$ Therefore, ketones and iodonium salt, forming two-component systems $(0.1 \% / 2 \%$, w/w), were utilized to initiate the cationic polymerization of EPOX upon the same LED@405 nm irradiation. However, the ketone-5/Iod system was not efficient for the cationic polymerization at all, and the ketone-2/Iod system could only induce the partial polymerization of EPOX in thin films condition. Typical epoxides function conversion against LED irradiation time profile is shown in Figure 5a, and the FC of epoxides after the same violet LED irradiation for $400 \mathrm{~s}$ was only about $33 \%$. The cationic polymerization of EPOX in the presence of ketone-2/Iod was further verified by the intensity decrement of the peak at $\sim 800 \mathrm{~cm}^{-1}$, which was assigned to the epoxide group (Figure 5b). ${ }^{38}$ All the above results demonstrated that in this work the ketones-based photoinitiating systems are effective for the free radical polymerization of acrylates, but less efficient for the cationic polymerization of epoxides.

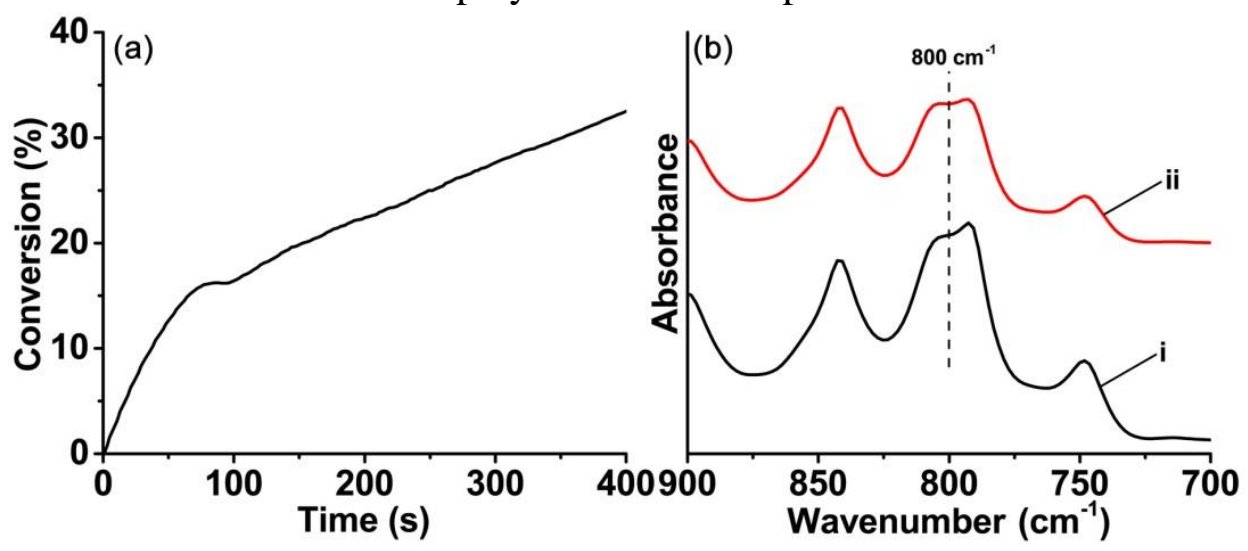


Figure 5. (a) Cationic photopolymerization profile of EPOX (conversion of epoxides versus irradiation time) initiated by ketone-2/Iod $(0.1 \% / 2 \%$, w/w) two-component system upon violet LED@405 nm irradiation at room temperature in thin films condition $(25 \mu \mathrm{m})$; (b) In-situ IR spectra recorded for EPOX (i) before and (ii) after the irradiation of LED@405 nm for $400 \mathrm{~s}$ in the presence of ketone-2/Iod in thin films condition.

\subsection{Steady state photolysis of ketones}

In order to investigate the photochemical mechanisms for the ketone/amine/Iod three-component systems, the steady state photolysis experiments were conducted first. Here ketone- 2 and ketone- 5 were selected as representative ketone derivatives for the photolysis study, considering their high photoinitiation abilities for the free radical polymerization in thick and thin films, respectively. Since the absorption maxima $\left(\lambda_{\max }\right)$ of these two ketones are around 370 nm, thus a LED@375 nm was utilized as the irradiation source for the photolysis characterization. The steady state photolysis experiments of ketone- 2 and ketone- 5 were performed separately with the amine (EDB) and the iodonium salt by a UV-visible spectrometer (Figure 6). As illustrated in Figure $6 \mathrm{a}$ and $6 \mathrm{c}$, both ketone- 2 and ketone- 5 showed a strong absorption between $350 \mathrm{~nm}$ and $450 \mathrm{~nm}$ in the presence of the amine. Then, upon irradiation with a LED @ $375 \mathrm{~nm}$, an obvious intensity decline could be observed with the two ketones. Moreover, the consumption percentage of ketones was calculated as a function of the LED irradiation time, which revealed a nonlinear relationship. In the presence of the amine, the final consumption of ketone-2 reached 32\% after 10 min. of irradiation with the LED@375 $\mathrm{nm}$ (Figure 6b). Conversely, the final consumption of ketone-5 reached $24 \%$, which is a little lower than that of ketone-2 (Figure $6 \mathrm{~d}$ ) for the same irradiation time. 

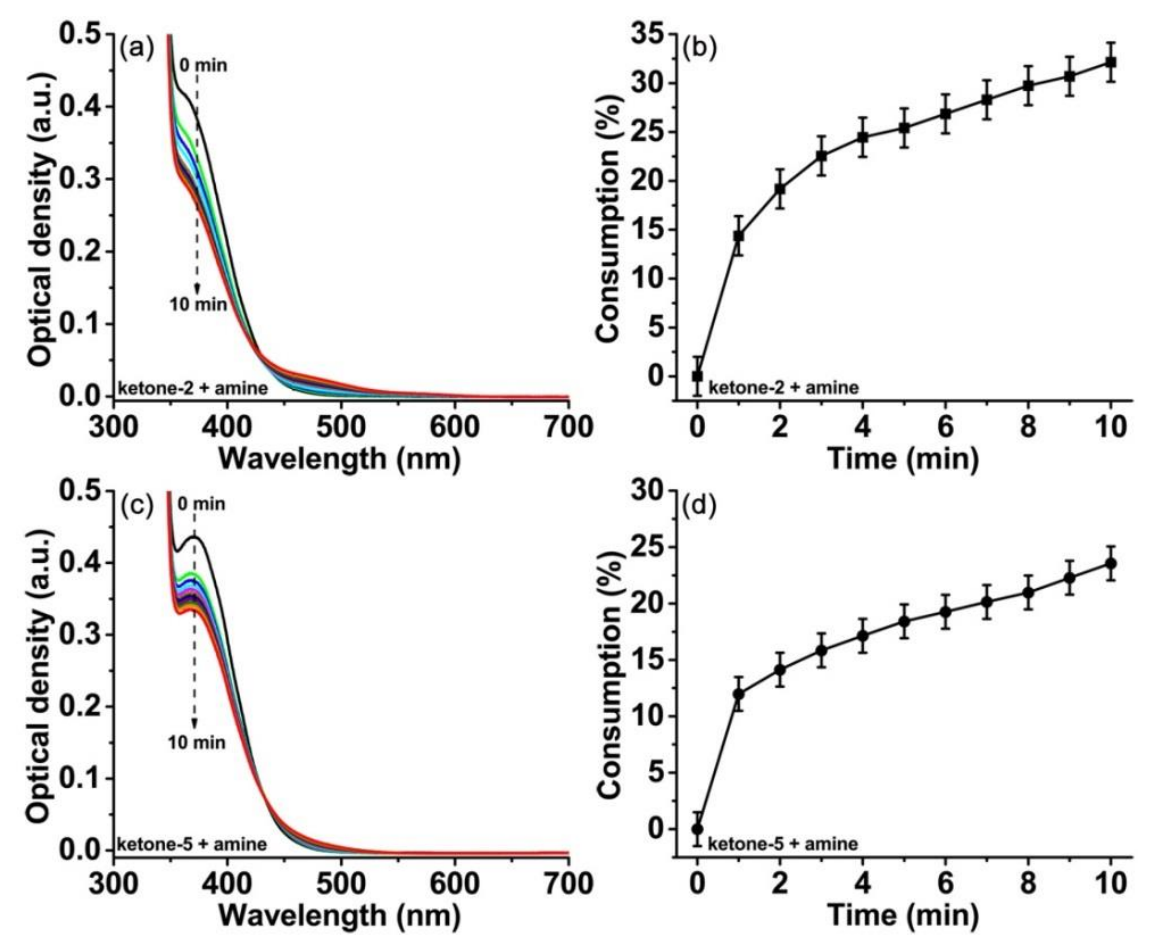

Figure 6. Left: UV-visible absorption spectra of (a) ketone-2 $\left(1.95 \times 10^{-5} \mathrm{M}\right)$ and (c) ketone-5 $\left(1.90 \times 10^{-5} \mathrm{M}\right)$ in the presence of amine $\left(\mathrm{EDB}, 1.0 \times 10^{-2} \mathrm{M}\right)$ in acetonitrile upon exposure to LED@375 nm irradiation for $10 \mathrm{~min}$. Right: Consumption of ketones vs. LED@375 nm irradiation time for (b) ketone-2/amine and (d) ketone-5/amine systems, respectively.

Similar steady state photolysis experiments of ketones were also performed in the presence of the iodonium salt, as illustrated in Figure 7. A strong absorption in the 350$450 \mathrm{~nm}$ range was also observed for the ketone/Iod two-component systems. Then, upon the same LED@375 nm irradiation, a dramatic intensity decline could be observed with the two ketones. Interestingly, along with the LED irradiation, a new absorption band in the range of $500 \mathrm{~nm}-600 \mathrm{~nm}$ gradually arose and became dominant (Figure 7a, 7c). The appearance of such a new absorption band between $500 \mathrm{~nm}$ and $600 \mathrm{~nm}$ implied the formation of a new photoproduct in this case, which is accordingly due to the strong interaction in the ketone/Iod system. ${ }^{39}$ An isobestic point is found in both cases in Figure 7a and 7c in agreement with a photochemical process without formation of by-side product. Especially, the photolysis of ketone-2 in the presence of the iodonium salt was accompanied with a clear colorimetric transition. As shown in Figure S5, the acetonitrile solution containing ketone-2/Iod turned from nearly colorless to obvious purple during the LED@375 nm irradiation. The percentage consumption of ketones in the presence of the iodonium salt was also calculated as a function of the LED irradiation time, and the final consumptions of ketone-2 and ketone-3 within 10 min reached about $67 \%$ and $62 \%$ (Figure 7b, 7d), respectively, which are much higher than those in the presence of amine. 

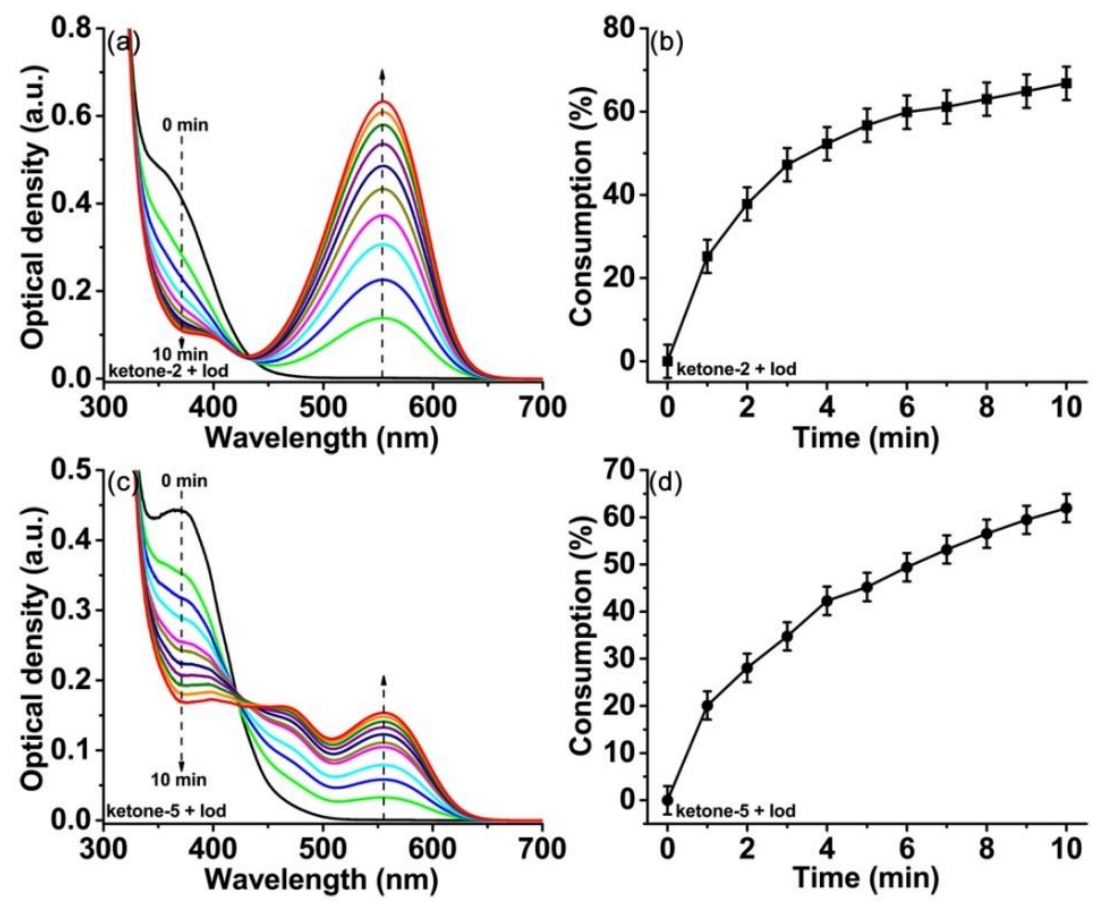

Figure 7. Left: UV-visible absorption spectra of (a) ketone-2 $\left(1.95 \times 10^{-5} \mathrm{M}\right)$ and (c) ketone-5 $\left(1.90 \times 10^{-5} \mathrm{M}\right)$ in the presence of iodonium salt $\left(1.0 \times 10^{-2} \mathrm{M}\right)$ in acetonitrile upon exposure to LED@375 nm irradiation for $10 \mathrm{~min}$. Right: Consumption of ketones vs. LED@375 nm irradiation time for (b) ketone-2/Iod and (d) ketone-5/Iod systems, respectively.

It's worth mentioning that in the absence of any photo-additives (i.e. amine and iodonium salt), the photolysis of ketones upon LED@375 nm irradiation could still take place. As shown in Figure S6, intensity of the maximum absorption in $300 \mathrm{~nm}-500 \mathrm{~nm}$ range exhibited an obvious decrement for ketone- 2 and ketone- 5 along with the LED irradiation. Moreover, the percentage consumption results of ketones in the absence and presence of photo-additives are summarized and compared in Table 3. From these different experiments, it can be concluded that the addition of photo-additives could promote the photolysis of ketones more efficiently than the ketones alone, especially for the ketone/Iod system. All these steady state photolysis results highlighted the photosensitivity for the ketone/amine/Iod three-component systems, and possible oxidation-reduction reaction mechanism was already proposed by us for other initiating systems (Scheme 4). ${ }^{21,22}$

Table 3. Consumption percentages of ketones with or without photo-additives through the steady state photolysis experiments upon LED@375 nm irradiation for $10 \mathrm{~min}$.

\begin{tabular}{|c|c|c|c|}
\hline & without additives & with amine & with Iod \\
\hline ketone-2 & $27 \%$ & $32 \%$ & $67 \%$ \\
\hline ketone-5 & $21 \%$ & $24 \%$ & $62 \%$ \\
\hline
\end{tabular}


(r1) ketone $\stackrel{\text { LED }}{\longrightarrow}$ ketone*

(r2) ketone* $+\mathrm{Ar} \stackrel{\oplus}{-}-\mathrm{Ar} \longrightarrow$ ketone $^{*+}+\mathrm{Ar}+\mathrm{ArI}$

(Iod)

(r3)
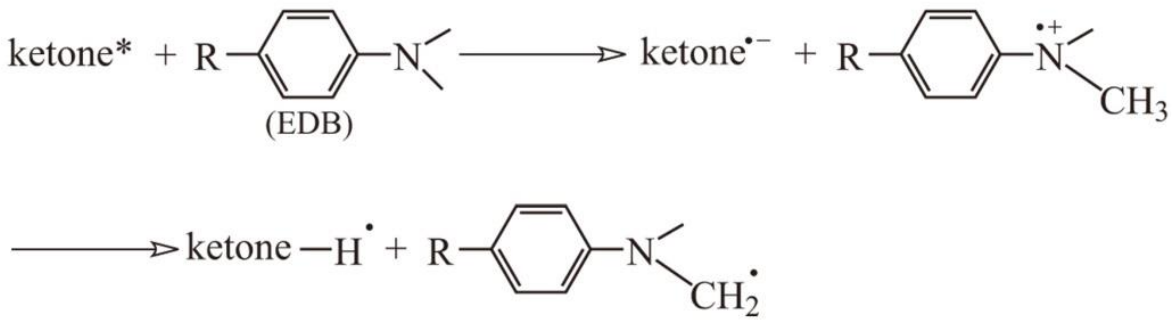

(r4) ketone $^{\cdot+}+\mathrm{EDB} \longrightarrow$ ketone $+\mathrm{EDB}^{\cdot+}$

(r5) ketone $-\mathrm{H}^{\cdot}+\mathrm{Ar} \stackrel{\oplus}{-}-\mathrm{Ar} \longrightarrow$ ketone $+\mathrm{Ar}+\mathrm{ArI}+\mathrm{H}$

Scheme 4. The photochemical oxidation-reduction reaction mechanism for the ketone/amine/Iod three-component initiating system.

\subsection{Fluorescence quenching of ketones}

The above steady state photolysis results suggested that the ketones were more reactive with the iodonium salt than with an amine, further excited state fluorescence and fluorescence quenching experiments in acetonitrile for the ketone derivatives were conducted. Although no obvious florescence quenching was observed for the ketones in the presence of the amine, the iodonium salt could induce a significant florescence quenching of ketones. As shown in Figure 8, both ketone- 2 and ketone-5 emitted a strong fluorescence signal in acetonitrile in the $400 \mathrm{~nm}-600 \mathrm{~nm}$ range. However, upon the increasing addition of the iodonium salt (Speedcure 938) from $0 \mathrm{M}$ to $\sim 4.0 \times 10^{-3}$ $\mathrm{M}$, a continuous and significant fluorescence quenching phenomenon was observed for these two ketones (Figure 8a, 8c). The Stern-Volmer treatment suggested that there is a linear relationship between the change of the fluorescence intensity and the concentration of the added iodonium salt (Figure $8 \mathrm{~b}, 8 \mathrm{~d}$ ). ${ }^{21}$ And the interaction constant $\left(K_{s v}\right)$ for ketone-2/Iod was about $226 \mathrm{M}^{-1}$, while the $K_{s v}$ for ketone-5/Iod was only 143 $\mathrm{M}^{-1}$. Further the electron transfer quantum yields $\left(\Phi^{e t}\right)$ for the fluorescence quenching experiments were calculated, and ketone-2/Iod ( $\Phi^{e t}$ ketone-2/Iod, 0.91) showed a little higher electron transfer quantum yield than that of ketone-5/Iod ( $\Phi^{e t}{ }_{\text {ketone-5/Iod, }} 0.86$ ), which is in accordance with the above photolysis experiments. The above results demonstrated that the iodonium salt was a good fluorescence quencher to the ketone derivatives and highlighted the strong interaction between ketone/Iod two-component systems. 

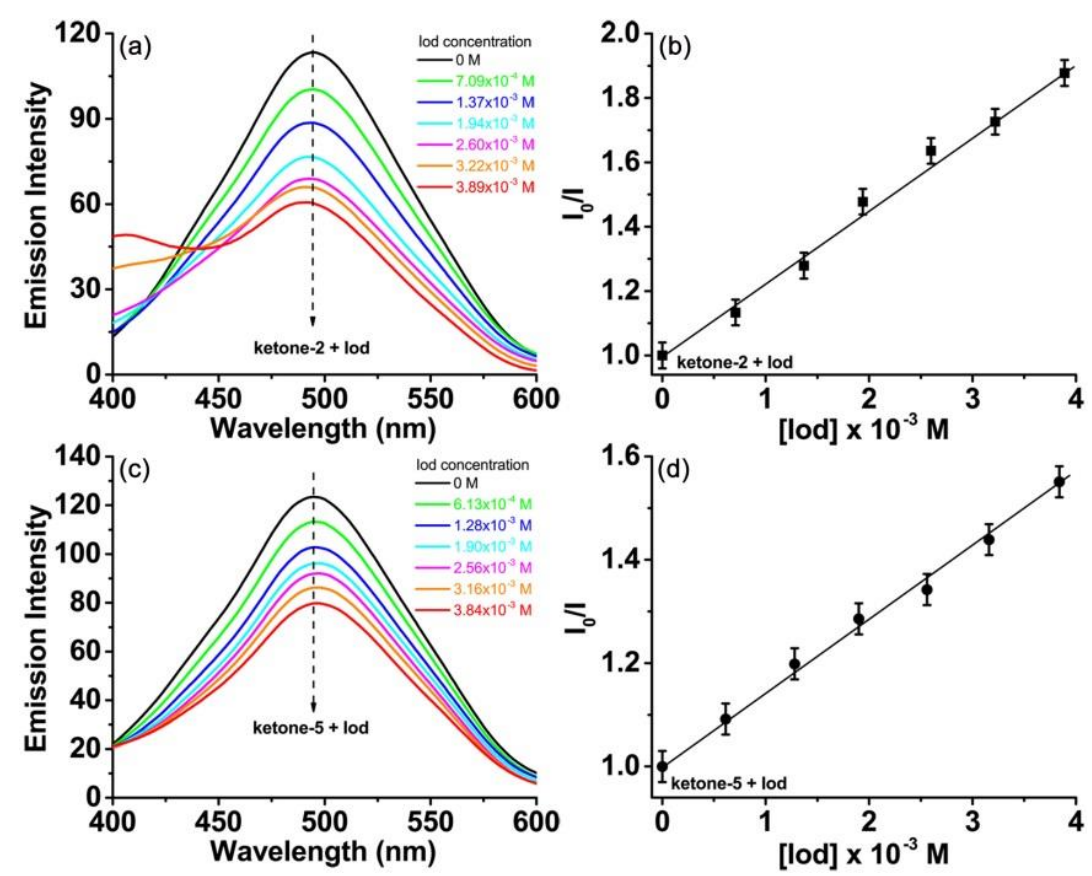

Figure 8. Left: Fluorescence quenching of (a) ketone-2 $\left(1.95 \times 10^{-5} \mathrm{M}\right)$ and (c) ketone$5\left(1.90 \times 10^{-5} \mathrm{M}\right)$ upon the increasing addition of iodonium salt (Speedcure 938) in the solvent of acetonitrile, $\lambda_{\mathrm{exc}}=320 \mathrm{~nm}$. Right: Stern-Volmer treatment for (b) ketone2/Iod and (d) ketone-5/Iod fluorescence quenching, respectively.

\subsection{Migration study of ketones}

The peripheral 1,3-bis(allyloxy)benzene substituting group in the ketone structure is supposed to improve the migration stability of ketones in the photocured TA. Indeed, the allyl group can be involved in the copolymerization with acrylate. ${ }^{40}$

With aim at evidencing the benefits of the polymerizable group, another ketone derivative, i.e. ketone-ref, sharing the same central cyclohexanone core with ketone-5 but without the allylic functionalities, was proposed as the reference ketone. In this last case, the aliphatic chains are not capable of crosslinking to the polymer network, contrarily to the allylic chains. Acetonitrile was selected as the appropriate solvent for the migration study. And the migration of ketone-5 and ketone-ref from the TA polymer, which was photocured in thick films condition $(1.4 \mathrm{~mm})$ using ketone/amine/Iod $(0.1 \% / 2 \% / 2 \%, \mathrm{w} / \mathrm{w} / \mathrm{w} /)$ three-component systems, was evaluated by UV-visible absorption measurements. As illustrated in Figure 9, about 8.3\% ketone-ref migrated from polymer to acetonitrile. However, less than $0.9 \%$ ketone- 5 migrated from polymer to the solvent. This low migration property of ketone- 5 is probably ascribed to both the highly crosslinked network of polymer structure and the presence of reactive $\mathrm{C}=\mathrm{C}$ double bond in the peripheral substituting group, which could be involved in a copolymerization reaction with the acrylate functions of TA. ${ }^{19}$ Therefore, the 1,3bis(allyloxy)benzene substituted ketone derivatives introduced in this work can demonstrate satisfactory migration stability. 
(a)<smiles>C=CCOc1ccc(/C=C2\CN(CC)CC(=Cc3ccc(OCC=C)c(OCC=C)c3)C2=O)cc1</smiles><smiles>CCN1CC(=Cc2cccc(Br)c2)C(=O)C(=Cc2ccc(Br)cc2O)C1</smiles>

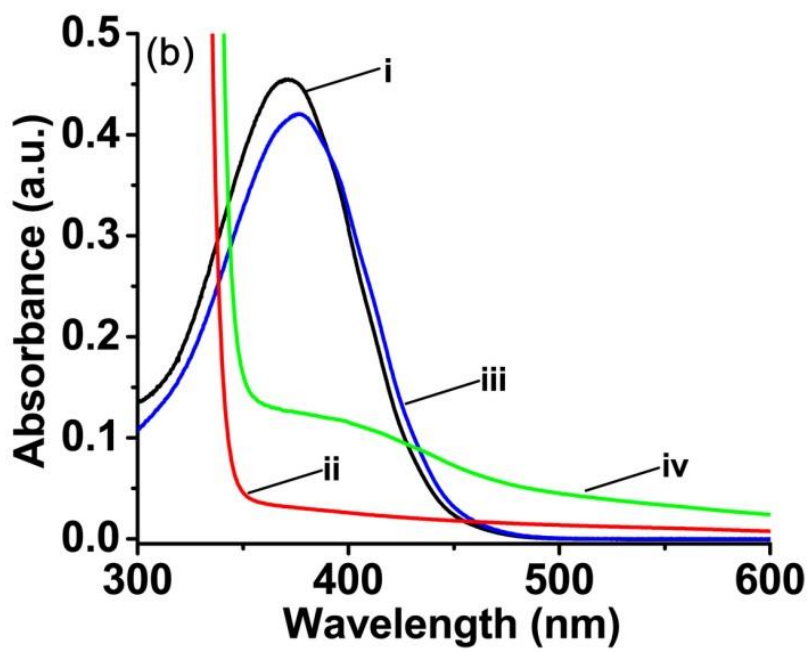

Figure 9. (a) Chemical structures of ketone-5 and ketone-ref; (b) UV-visible absorption spectra of ketones: (i) ketone-5 in acetonitrile $(0.01 \mathrm{mg} / \mathrm{mL})$, (ii) ketone-5 migrating from polymer to acetonitrile, (iii) ketone-ref in acetonitrile $(0.01 \mathrm{mg} / \mathrm{mL})$ and (iv) ketone-ref migrating from polymer to acetonitrile, respectively.

\subsection{Laser write experiments}

Laser write experiments of TA upon laser diode irradiation at $405 \mathrm{~nm}$ were performed under air using the ketone-2/amine/Iod and ketone-5/amine/Iod threecomponent photoinitiating systems, respectively. The high photosensitivity and high photoinitiation ability of these two ketones-based photoinitiating systems allowed for an efficient free radical polymerization in the irradiated area. Interestingly, macroscopic patterns with really tridimensional structures (>1 mm thickness) were generated within a very short time ( $<1 \mathrm{~min}$ for a $1 \mathrm{~cm}$ length pattern). A photograph of the generated patterns with pink color is shown in Figure S7. The 3D patterns, "WZY", were clearly observed and analyzed via numerical optical microscopy, as shown in Figure 10. The step width between the photocuring resin and the non-curing resin was about $50 \mu \mathrm{m}$, which is in accordance with the spot size of the laser beam, thus exemplifying an excellent spatial resolution. ${ }^{41,42}$ The laser write results of TA set a good example for the effective free radical polymerization of acrylates initiated with the ketones-based threecomponent photoinitiating systems.

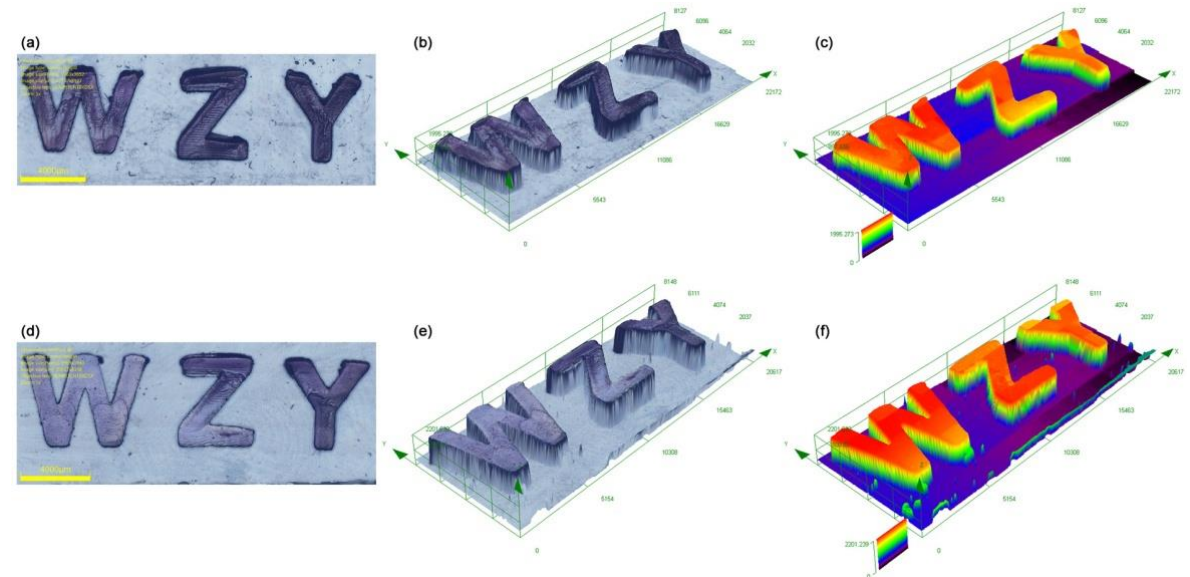


Figure 10. Free radical photopolymerization experiments for laser write upon laser diode irradiation at $405 \mathrm{~nm}$ with ketones-based photoinitiating systems and characterization of the generated 3D patterns by numerical optical microscopy. (Up) for ketone-2/amine/Iod: (a) top surface morphology and 3D overall appearance in (b) black-and-white and (c) color patterns; (down) for ketone-5/amine/Iod: (d) top surface morphology and 3D overall appearance in (e) black-and-white and (f) color patterns, respectively. The scale bar is $4000 \mu \mathrm{m}$.

\section{Conclusion}

In summary, in this work, five ketone derivatives bearing the same peripheral substituting group, i.e. 1,3-bis(allyloxy)benzene, were examined for the first time as photoinitiators. It has to be noticed that none of the ketones examined in this work have been reported in the literature and never synthesized before. The ketone/amine/Iod, forming three-component photoinitiating systems were studied with RT-FTIR to explore their initiation abilities for the free radical polymerization of TA upon violet LED@405 nm irradiation at room temperature. The distinct initiation abilities of these ketones were probably ascribed to their various central cyclohexanone structures. Among all these ketones, the ketone-2 based photoinitiating system exhibited the highest initiation efficiency for the free radical polymerization in thick films condition, and the ketone-5 based system exhibited the highest initiation efficiency for the free radical polymerization in thin films condition. Ketone-2, in combination with the iodonium salt, was also studied for the cationic polymerization of epoxides, but only a partial polymerization was achieved with a lower efficiency than that observed during the FRP of acrylates. Photosensitivity of ketone- 2 and ketone-5, in the presence of the amine or the iodonium salt, were systematically investigated with UV-visible absorption and fluorescence spectroscopy. Interestingly, excellent migration stability was observed for these ketones containing reactive double bonds in the peripheral groups. Additionally, ketone-2 and ketone-5 based three-component photoinitiating systems found promising applications in laser writing experiments to produce truly tridimensional patterns with excellent spatial resolution.

\section{Acknowledgments}

Yangyang $\mathrm{Xu}$ is thankful to the financial support from the Anhui Provincial Natural Science Foundation (1808085QB42), Natural Science Fund of Education Department of Anhui Province (KJ2018A0307), and China Scholarship Council (CSC). Pu Xiao acknowledges funding from the Australian Research Council (FT170100301). The Agence Nationale de la Recherche (ANR agency) is acknowledged for its financial support through the PhD grant of Guillaume Noirbent (ANR-17-CE08-0054 VISICAT project). The Direction Générale de l'Armement (DGA)/Agence Innovation Defense (AID) is acknowledged for its financial support through the $\mathrm{PhD}$ grant of Damien Brunel. This work was granted access to the HPC resources of the Mesocentre of the University of Strasbourg. 


\section{References}

1. G. Yilmaz and Y. Yagci, Prog. Polym. Sci., 2020, 100, 101178.

2. A. Banerji, K. Jin, K. Liu, M. K. Mahanthappa and C. J. Ellison, Macromolecules, 2019, 52, 6662-6672.

3. N. Corrigan, J. Yeow, P. Judzewitsch, J. Xu and C. Boyer, Angew. Chem. Int. Ed., 2019, 58, 5170-5189.

4. F. Jasinski, P. B. Zetterlund, A. M. Braun and A. Chemtob, Prog. Polym. Sci., 2018, 84, 47-88.

5. H. Lai, J. Zhang, F. Xing and P. Xiao, Chem. Soc. Rev., 2020, 49, 1867-1886.

6. L. Tang, J. Nie and X. Zhu, Polym. Chem., 2020, 11, 2855-2863.

7. Y. Liu, Y. Lin, T. Jiao, G. Lu and J. Liu, Polym. Chem., 2019, 10, 6350-6359.

8. A. C. Weems, K. R. D. Chiaie, J. C. Worch, C. J. Stubbs and A. P. Dove, Polym. Chem., 2019, 10, 5959-5966.

9. J. J. Schwartz and A. J. Boydston, Nat. Commun., 2019, 10, 791.

10. Y. Xu, C. Jambou, K. Sun, J. Lalevée, A. Simon-Masseron and P. Xiao, ACS Appl. Polym. Mater., 2019, 1, 2854-2861.

11. N. Klikovits, L. Sinawehl, P. Knaack, T. Koch, J. Stampfl, C. Gorsche and R. Liska, ACS Macro Lett., 2020, 9, 546-551.

12. Y. Xu, S. Fu, F. Liu, H. Yu and J. Gao, Soft Matter, 2018, 14, 8044-8050.

13. F. Dumur, D. Gigmes, J.-P. Fouassier and J. Lalevée, Acc. Chem. Res., 2016, 49, 1980-1989.

14. P. Xiao, J. Zhang, F. Dumur, M. A. Tehfe, F. Morlet-Savary, B. Graff, D. Gigmes, J. P. Fouassier, J. Lalevée, Prog. Polym. Sci., 2015, 41, 32-66.

15. J. Yu, Y. Gao, S. Jiang and F. Sun, Macromolecules, 2019, 52, 1707-1717.

16. W. Qiu, M. Li, Y. Yang, Z. Li and K. Dietliker, Polym. Chem., 2020, 11, 1356-1363.

17. Y.-H. Li and Y.-C. Chen, Polym. Chem., 2020, 11, 1504-1513.

18. P. Xiao, F. Dumur, D. Thirion, S. Fagour, A. Vacher, X. Sallenave, F. MorletSavary, B. Graff, J. P. Fouassier, D. Gigmes and J. Lalevée, Macromolecules, 2013, 46, 6786-6793.

19. E. Ay, Z. Raad, O. Dautel, F. Dumur, G. Wantz, D. Gigmes, J.-P. Fouassier and J. Lalevée, Macromolecules, 2016, 49, 2124-2134.

20. B. Graff, J. E. Klee, C. Fik, M. Maier, J. P. Fouassier and J. Lalevée, Macromol. Rapid Commun., 2017, 38, 1600470.

21. K. Sun, Y. Xu, F. Dumur, F. Morlet-Savary, H. Chen, C. Dietlin, B. Graff, J. Lalevée and P. Xiao, Polym. Chem., 2020, 11, 2230-2242.

22. Y. Xu, G. Noirbent, D. Brunel, F. Liu, D. Gigmes, K. Sun, Y. Zhang, S. Liu, F. Morlet-Savary, P. Xiao, F. Dumur and J. Lalevée, Eur. Polym. J., 2020, 132, 109737.

23. J. Yang, W. Liao, Y. Xiong, Q. Wu, X. Wang, Z. Li and H. Tang, Dyes Pigments, 2018, 148, 16-24.

24. J. Yang, C. Xu, Y. Xiong, X. Wang, Y. Xie, Z. Li and H. Tang, Macromol. Chem. Phys., 2018, 219, 1800256. 
25. J. Yang, W. Liao, Y. Xiong, X. Wang, Z. Li and H. Tang, Prog. Org. Coat., 2018, 115, 151-158.

26. P. Xiao, F. Dumur, M. Frigoli, M.-A. Tehfe, B. Graff, J. P. Fouassier, D. Gigmes and J. Lalevée, Polym. Chem., 2013, 4, 5440-5448.

27. A. A. Mousawi, P. Garra, F. Dumur, B. Graff, J. P. Fouassier and J. Lalevée, J. Polym. Sci., 2020, 58, 254-262.

28. M. Abdallah, H. Le, A. Hijazi, M. Schmitt, B. Graff, F. Dumur, T.-T. Bui, F. Goubard, J.-P. Fouassier and J. Lalevée, Polymer, 2018, 159, 47-58.

29. M. Abdallah, A. Hijazi, B. Graff, J.-P. Fouassier, F. Dumur and J. Lalevée, ACS Appl. Polym. Mater., 2020, 2, 2890-2901.

30. Y.-Y. Xu, Z.-F. Ding, F.-Y. Liu, K. Sun, C. Dietlin, J. Lalevée and P. Xiao, ACS Appl. Mater. Interfaces, 2020, 12, 1658-1664.

31. A. A. Mousawi, D. M. Lara, G. Noirbent, F. Dumur, J. Toufaily, T. Hamieh, T.-T. Bui, F. Goubard, B. Graff, D. Gigmes, J. P. Fouassier and J. Lalevée, Macromolecules, 2017, 50, 4913-4926.

32. A. A. Mousawi, F. Dumur, P. Garra, J. Toufaily, T. Hamieh, B. Graff, D. Gigmes, J. P. Fouassier and J. Lalevée, Macromolecules, 2017, 50, 2747-2758.

33. E. Hola, J. Ortyl, M. Jankowska, M. Pilch, M. Galek, F. Morlet-Savary, B. Graff, C. Dietlin and J. Lalevée, Polym. Chem., 2020, 11, 922-935.

34. D. Wang, P. Garra, F. Szillat, J. P. Fouassier and J. Lalevée, Macromolecules, 2019, 52, 3351-3358.

35. P. Garra, B. Graff, F. Morlet-Savary, C. Dietlin, J.-M. Becht, J.-P. Fouassier and J. Lalevée, Macromolecules, 2018, 51, 57-70.

36. A. A. Mousawi, C. Poriel, F. Dumur, J. Toufaily, T. Hamieh, J. P. Fouassier and J. Lalevée, Macromolecules, 2017, 50, 746-753.

37. P. Xiao, F. Dumur, J. Zhang, B. Graff, D. Gigmes, J. P. Fouassier and J. Lalevée, Polym. Chem., 2015, 6, 1171-1179.

38. A. A. Mousawi, P. Garra, X. Sallenave, F. Dumur, J. Toufaily, T. Hamieh, B. Graff, D. Gigmes, J. P. Fouassier and J. Lalevée, Macromolecules, 2018, 51, 1811-1821.

39. M. Abdallah, A. Hijazi, B. Graff, J.-P. Fouassier, G. Rodeghiero, A. Gualandi, F. Dumur, P. G. Cozzi and J. Lalevée, Polym. Chem., 2019, 10, 872-884.

40. R. Venkatesh, F. Vergouwen and B. Klumperman, J. Polym. Sci. Pol. Chem., 2004, 42,3284-3271.

41. M. Abdallah, T.-T. Bui, F. Goubard, D. Theodosopoulou, F. Dumur, A. Hijazi, J.P. Fouassier and J. Lalevée, Polym. Chem., 2019, 10, 6145-6156.

42. M. Abdallah, F. Dumur, A. Hijazi, G. Rodeghiero, A. Gualandi, P. G. Cozzi, J. Lalevée, J. Polym. Sci., 2020, 58, 1115-1129. 


\section{TOC graphic:}

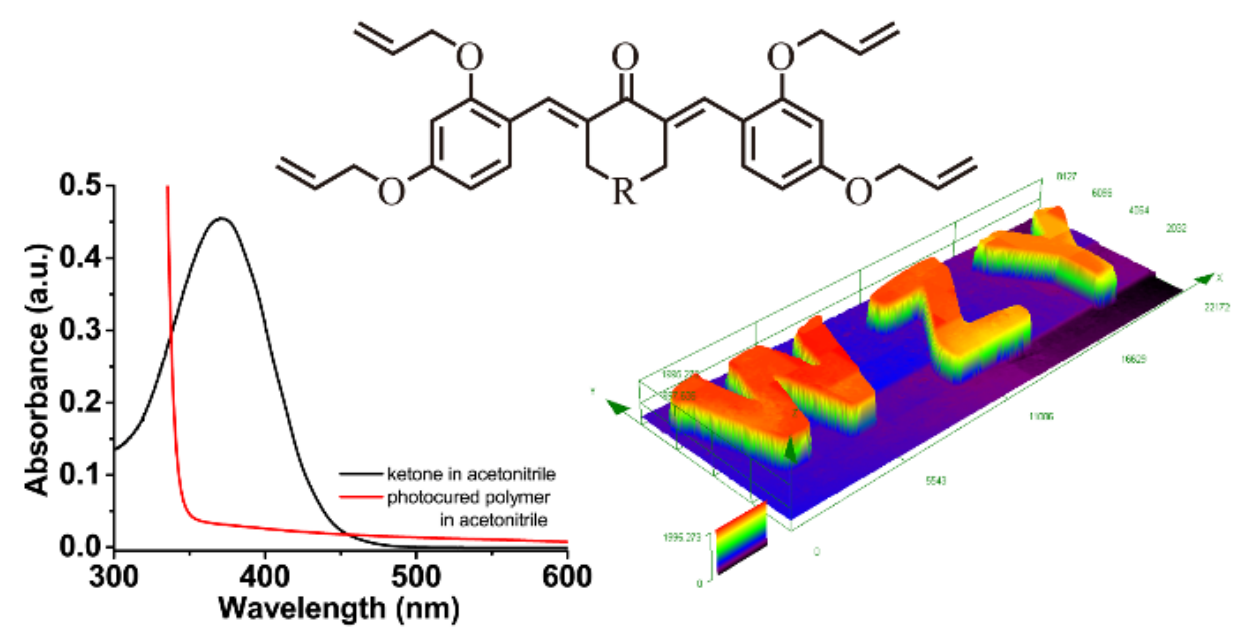

Allyloxy substituted ketone derivatives as efficient photoinitiators for free radical polymerization with low migration properties and application in 3D printing. 